\title{
Iconic images, symbols, and archetypes: their function in art and science
}

\author{
Frances R. Westley ${ }^{1,2}$ and Carl Folke ${ }^{3,4}$
}

ABSTRACT. The relationship between art and science is one of contrasts and commonalities. We look at one commonality between art and science: the central role of iconic images. We argue that iconic images are the touchstone symbols in both art and science and provide similar functions for both. We propose that these iconic images provoke an openness and a receptivity to our deepest emotional capacities and a connection between those and the dynamics of the broader social-ecological systems in which we operate. Such iconic images may also act as attractors that provoke the emergence of increasing levels of intellectual and aesthetic self-organization, not only at an individual level, but also in terms of larger social, scientific, or artistic fields. Finally, through a combination of this attraction and this connection, iconic images may play a role in transformation.

Key Words: iconic images; reconciling art and science; symbols; transformation

\section{INTRODUCTION}

The theologian Paul Tillich once observed that the chief curse of our time is not that we are evil, though often we are, but that we are banal, superficial. The recovery of depth will never come through an act of intellect, unless that intellect is in service to wonder. We can recover depth, however, by opening ourselves to the numinous which nods at us and invites us. We can also use our imaginative power to seize such moments of beckoning and the images which rise spontaneously from them. (Hollis 2000:30)

The idea of reconciling art and science is an enduring one. Without art, science becomes too rational (Kahneman 2011), too routine (Kuhn 1962), and too detached from the broad systemic shifts that are currently affecting our planet (Wilson 1998, Gould 2000). Without science, artistic productivity can become shallow, purely emotive, or lacking in technique and precision. Reconciling art and science, although not easy, can be seen to have many advantages for scientists working on contemporary issues. Art can act to give scientific findings much broader appeal and resonance (Curtis et al. 2012, Vervoot et al. 2014). It has lessons to teach scientists about how the brain works and perceives (Österblom et al. 2015). It can stimulate intuitive, creative, and revolutionary approaches to problems (Uzzi et al. 2013, Scheffer et al. 2015), and connecting artists and scientists can catalyze an increase in creative approaches in both (Root-Bernstein 2000, Evans and Jones 2008).

We will look at one particular arena in which art and science are aligned: the importance and use of iconic imagery and symbols. We use both the terms "icon/iconic" and "symbol/symbolic" to identify the same pictures and objects. We recognize that these terms have different meanings. According to C. S. Peirce, an icon is "a sign which is determined by its dynamic object by virtue of its own internal nature ... (for example) the sentiment excited by a piece of music as representing what the composer intended" (Peirce 1958/1899:228). In other words, the icon, which could be any production, e.g., a portrait, a diagram, or a photograph, closely resembles, even imitates, its object and is capable of generating a similar response as the real object. A symbol, on the other hand, "is a sign which is determined by its object only in the sense that it will be so interpreted. It thus depends either on a convention, a habit or a natural disposition of its interpretant"
(Peirce 1958/1899:228). Symbols, unlike icons, do not depend for their impact on resemblance to the real object represented. It is through the interpretation of the viewer that the symbol, e.g., book, theory, person, flag, or animal, draws its power. We interpret this distinction as important, but we will explore how these two kinds of signs can be conflated in both art and science. The two are separated in part by the degree of abstraction: icons, as Peirce describes them, being more closely tied to the object they represent, and symbol being sufficiently removed or abstracted from that object to require interpretation. We will argue that certain images, pictures, and artistic or scientific representations initially become "iconic," in the more popular sense of "widely known and acknowledged especially for distinctive excellence" (https://www.merriam-webster.com/dictionary/iconic), precisely because of the way in which the image captures the "truth" or nature of an object, and so is closely related to that object. However, iconic images also are associated with whole schools of thought or practice and hence become symbols, reference points for a continued interpretative debate. It is this process of interpretation, we will argue, that in fact drives the development of fields of thought. It is therefore this latter process, the use of symbols, on which we will mostly focus.

In both art and science, throughout history, some images have retained their resonance, being considered masterpieces in art and touchstones in science that shape the public imagination. We think of such iconic paintings as da Vinci's Mona Lisa or Van Gogh's Starry Night. In the 20th century, photographic images such as Eddie Adams's General Nguyen Ngoc Loan killing Viet Cong Suspect Nguyen during the Tet Offensive, taken in 1968; Charlie Cole's photo of Tank Man, a man standing in front of a column of tanks in Tiananmen Square; and Arthur Sasse's photo of Albert Einstein sticking out his tongue have become touchstones, defining public opinion of events and people. In science, the 1972 photo Blue Marble, a shot of the earth from space, is an image that inspired many scientists to engage with environmental issues and sustainability; the image of the double helix and the images of fractals in nature have become reference points of whole fields of exploration.

What is the significance of such imagery? How does it function in stimulating artistic and scientific activity? We will treat such images as symbols and draw on the long history of work in social

${ }^{1}$ Waterloo Institute for Social Innovation and Resilience, ${ }^{2}$ School for Environment, Enterprise and Development, University of Waterloo,

${ }^{3}$ Stockholm Resilience Centre, Stockholm University, Sweden, ${ }^{4}$ Beijer Institute, Royal Swedish Academy of Sciences, Sweden 
science and philosophy on symbols and their function. In particular, we will draw on Jungian psychology and contemporary thinking about complexity theory and archetypes to argue that iconic imagery has an important but often neglected role in both art and science.

We propose that these iconic images provoke an openness and a receptivity to our deepest emotional capacities and a connection between those and the dynamics of the broader social-ecological systems in which we operate. Such iconic images may also act as attractors that provoke the emergence of increasing levels of intellectual and aesthetic self-organization, not only at an individual level, but also in terms of larger social, scientific, or artistic fields. Finally, through a combination of this attraction and this connection, iconic images may play a role in transformation. These three capacities, for connection, for selforganization, and for transformation, have never been more in demand (Westley et al. 2011).

\section{THE NATURE OF SYMBOLS AND THE SYMBOLS OF NATURE}

Many philosophers, linguists, and aestheticians have written about the nature of symbols, few more powerfully and succinctly than the theologian Paul Tillich (1957). He identifies six aspects that define a symbol.

1. Symbols express the "ultimate"; they "point beyond themselves to something beyond the self" (Tillich 1957:73). Take, for example, the double helix. At the time that Crick and Watson created the model, the only empirical evidence of the structure of DNA was in the X-ray defraction images that Rosalind Franklin had taken. The model (Fig. 1) that Crick created was a coming together and synthesis of Franklin's work and others' experimental findings regarding DNA. It was the embodiment of a theory, one so elegant that it immediately took hold of the imagination. However, it pointed to as many questions as it did answers. Similar examples abound in the visual arts, such as the cubist school, whose works disassemble the surface of objects to reveal the kinetic energy underneath (Fig. 2). In cubism, the objects are analyzed, broken up, and reassembled in an abstracted form, opening up the possibility of multiple viewpoints embedded in a single form.

2. This leads to the second characteristic of the symbol: "It participates in that to which it points" (Tillich 1957:73). Again, in the case of the double helix, the model itself became an attractor for further exploration that stimulated an acceleration of work on genetics. Similarly, the Mandelbrot set (Fig. 3), with its beautiful images, made what was a mathematical equation concrete and visual and stimulated exploration of the fractals that went far beyond mathematics, influencing social and natural scientists (Westley et al. 2006). Iconic images such as Cezanne's paintings of Mont Sainte-Victoire forever changed the perception of the landscape. Such images became part of the experience of a three-dimensional form, of a new landscape, so that the image and the reality merge (Fig. 4). Such images also inspired the emergence of cubism, pioneered by artists such as Picasso and Braque, a visual art form that spread rapidly across the globe.
3. The third characteristic of a symbol is that "it opens up levels of reality that otherwise are closed for us" (Tillich 1957:74). Tillich felt this was particularly a quality of the arts: Artists create symbols that represent a level of human experience that cannot be reached any other way. Through a poem or an iconic image that has symbolic status, we access emotional and spiritual realms, which, Tillich argued, "cannot be approached scientifically." We would agree with the capacity of the arts to reach such a dimension but argue that the iconic images of science, like those of art, point to what David Bohm (1980) would call implicate reality, which cannot be directly observed by scientists until it has unfolded in some form. Take, for example, Leonardo da Vinci's iconic Vitruvian Man (Fig. 5), a work of both art and science that hints at a theory of the order underlying form that goes beyond conventional measurement and direct observation.

4. The symbol's fourth characteristic is that "it not only opens up dimensions and elements of reality, which otherwise would remain unapproachable, but also unlocks dimensions and elements of our soul that correspond to the dimensions and elements of reality" (Tillich 1957:74). This connection between inner and outer world has not been explored as thoroughly in contemporary science as in art. Artists throughout time have shared the belief that, as the Norwegian artist Edvard Munch once said, nature is not only all that is visible to the eye, but also includes the inner pictures of the soul.

Historically, in philosophy, this link was much explored. Aristotle argued that the aim of art is to represent not the appearance of things, but their inward significance. The link between the inner motivation and outer-world challenges, like climate change, is reflected in work on transformation, emphasizing shifts in consciousness and awareness, in beliefs, values, and worldviews, thereby challenging the individual to reflect on change itself (O'Brien and Hochachka 2010). Research has revealed a close connection between inward psychological well-being and exposure to nature, such as proximity to green space, gardens, or forests. Happiness and subjective well-being and a sense of meaning and purpose in life become unlocked and enhance imagination and creativity.

Iconic images of nature, such as trees, have served as power symbols in many cultures and mythologies and still do. The symbolic nature of trees appears and reappears in science and art, exposing our essence to new dimensions and elements. Charles Darwin used the concept of the tree of life in the context of the theory of evolution. Contemporary examples include the construction of visual trees of life based on genome sequences (e.g., Hug et al. 2016) and the use of trees as symbols in films, such as the Tree of Souls in James Cameron's 2009 movie Avatar, and within art as a symbol of our embeddedness in the biosphere (Fig. 6). As expressed by Pablo Picasso in the 1950s, "There are painters who transform the sun into a yellow spot, but there are others who with the help of their art and their intelligence transform a yellow spot into the sun" (http://www. goodreads.com/author/quotes/3253.Pablo Picasso). 
5. "Symbols cannot be produced intentionally"; this is the fifth characteristic (Tillich 1957:74). Tillich argues that an image becomes a symbol because it appeals to the unconscious part of our being. Symbols gain their power because they give expression to the feelings that hold together a human group. In this sense, they are like totems, representing the inner spirit or "collective essence," the bond that holds a social group together (Durkheim 2001 [1912]). The most powerful symbols, such as those associated with religions, attract many people and over a long history. Others, such as the Mandelbrot set and the double helix, express a quest for deeper understanding that may appeal to a subgroup and for a shorter period. In visual art, for example, some paintings are iconic for certain schools of artists, pointing to a new understanding, a new pathway that other artists seek to explore, such as the early impressionist paintings or early minimalist works by artists like Malevich and Mondrian, and others are iconic for the general public and may endure as iconic images for decades and even centuries, such as da Vinci's Mona Lisa or Munch's The Scream. Of course, these iconic images were the intentional products of scientists and artists. However, what Tillich means is that only the response of people who engage with and are attracted to or touched by the image makes it a symbol. Symbols cannot be consciously designed by the producer.

6. The sixth and last characteristic of the symbol is a consequence of the fact that "symbols ... are like living beings, they grow and they die" (Tillich 1957:74). When particular iconic images no longer produce the same emotional response of curiosity, attraction, or intensity, they lose their symbolic power and become empty icons, pointing to a moment in historical time but no longer alive. This may be because, in science or aesthetics, thinking and feeling about a particular subject has evolved and the once iconic symbol no longer has the same capacity to illuminate and intrigue. Or it may be that the context has shifted, so that the beliefs that were once embodied by the iconic imagery have lost their credibility. What was once evocative and mysterious becomes a cliché. Examples include the loss of significance of landscape portraits with the emergence of photography or the fading of revolutionary symbols when associated political movements and systems fail.

\section{THE FUNCTION OF ICONIC IMAGES AS SYMBOLS IN ART AND SCIENCE}

In addition to these six characteristics identified for all symbols, we argue that iconic imagery has three important roles or functions in both art and science, ones that are particularly relevant for the interdisciplinary work in sustainability science. These three roles or functions are described subsequently.

Iconic images are symbols reconnecting us to deeper and broader aspects of our human nature and the natural world

Underneath these cultural splits, the archetypal imagination seeks, through affectively charged images, to connect us to the flow of energy that is the heart and hum of the cosmos. (Hollis 2000:10)

For anyone learning to gather wild mushrooms, the process first starts with recognizing a single edible mushroom. With time, however, that mushroom comes to be seen in context, the context of specific environments, for example, dead and degrading trees. We then see an even more detailed pattern particular to each type of mushroom: For example, the oyster mushroom grows on only on dead maple trees. In turn, we recognize the mushroom in the context of a particular type of forest or field and a particular type of dynamic (season or weather conditions). The initial mushroom of our search is intricately linked to these broader interconnections and dynamics, but we only learn to see the "bigger picture" by encountering and attending to one particular mushroom (Conforti 2013). It is there we start to explore and learn. The journey becomes one of curiosity, a search for a deeper or broader reality.

This example points to a belief held by many biologists, physicists, and complexity theorists alike that beneath the visible surface of form lies an "implicate order" (Bohm 1980). Implicate order is a deeper reality, from which all form emerges. As Bohm describes it,

In the enfolded [or implicate] order, space and time are
no longer the dominant factors determining the
relationships of dependence or independence of different
elements. Rather, an entirely different sort of basic
connection of elements is possible, from which our
ordinary notions of space and time, along with those of
separately existent material particles, are abstracted as
forms derived from the deeper order. These ordinary
notions in fact appear in what is called the "explicate"
or "unfolded" order, which is a special and distinguished
form contained within the general totality of all the
implicate orders. (Bohm 1980:xv)

The single mushroom is the explicate or unfolded order of the broader set of conditions that make it manifest. It points to those underlying conditions calling us to apprehend a dynamic of system interactions that lies behind the manifest. For Carl Gustav Jung, the individual human psyche is like the mushroom: What is manifest in personality, in beliefs, and in identity is the surface manifestation of an underlying dynamic, which at its deepest level connects all individuals in a "collective unconscious," the implicate order of the human species. Jung writes that

In addition to our immediate consciousness, which is of
a thoroughly personal nature and which we believe to be
the only empirical psyche (even if we tack on the personal
unconscious as an appendix), there exists a second
psychic system of a collective, universal, and impersonal
nature which is identical in all individuals. This collective
unconscious doesnot develop individually but is inherited.
It consists of pre-existent forms, the archetypes, which
can only become conscious secondarily and which give
definiteform to certain psychic contents. (Jung 1959/1969:43)

The collective unconscious then is proposed by Jung to be the source of emergent order in the human psyche. Its first form is the archetype, which Jung saw as a "typical mode of apprehension" of responding to and making sense of the world (Jung 1959/1969:43). It is typical in the sense that the pattern of behavior of any species is in part determined by its genetic makeup and phylogeny. Just as our physical form is the manifestation of phylogenetic history, so Jung argues the archetypes are a manifestation of the social, spiritual, and biological makeup and 
experience of the human race (Lu 2012). The archetypes, Jung argues, are not immediately accessible to the conscious mind:

They evidently live and function in the deeper layers of the unconscious, especially in that phylogenetic substratum which I have called the collective unconscious. This localization explains a good deal of their strangeness: they bring into our ephemeral consciousness an unknown psychic life belonging to a remote past. It is the mind of our unknown ancestors, their way of thinking and feeling, their way of experiencing life and the world, gods and men. (Jung 1959/1969:286-287)

It would not be too much of a stretch to treat the archaic strata and the implicate order as concepts that point to a similar phenomenon: the "ground of being" (Huxley 1946, Tillich 1951) from which all order emerges, a concept both mystical (at the heart of many of the world religions), philosophical (Plato), and theoretical. It is in this "ground of being" that humans are most closely connected to the reality of being embedded in the biosphere, the thin layer of life on planet Earth. It is "the very core of our being as well as the cause and basis of the universe of which we are part, we can no more get away from it than our solar system can get away from the sun round which it resolves and from which it receives everything which keeps it alive and moving" (Taimni 1974:1-2).

This brings us back to iconic images and symbols. Just as the single biological form may be treated as the manifestation of implicate order, so symbols, particularly those that endure, are seen by Jungians as the visual manifestation of archetypes, processed through the unconscious mind of the individual, into the conscious mind, and then represented in visual form in the world. Hence symbols, according to Jung, are the manifestation of the collective unconscious, the implicate order of human existence. The greater the appeal and attraction of such symbols, and the longer that attraction endures, the more likely it is that they are connected to the deepest levels of the collective unconscious. It is this unconscious to which a symbol draws our attention, in the same way that the mushroom draws our intention over time to a much broader pattern, or as suggested by Hollis:

Thus, as carriers of the same energy which animates the cosmos, we employ the archetypal imagination as the power of constitutive ordering which makes meaning possible. This "transcendent function," as Jung called it, not only links us with ourselves, bridging the conscious world with the unconscious through the venues of somatic symptom, affect, vision, and dream image, but also links us to superordinate reality through the symbolic powers. (Hollis 2000:15)

However, symbols, as the previous quote suggests, also bring our attention to the way in which our collective unconscious is in turn intertwined with the broader implicate order of the biosphere of which we as humans are a part and with which we have evolved. At the deepest levels, our own psyches are part and parcel of an energy that infuses all life-forms and the biosphere itself. Iconic imagery points us toward these deeper levels. Both groups, artists and scientists, are explorers and seekers of this "deeper" meaning.
Symbols as attractors that stimulate the emergence of new order and understanding

In the First Nation Ojibwa tradition, myths and legends feature archetypal creators, such as "the Trickster" (raven/spider/coyote), who act to turn order into disorder. These stories are told in short form to children and, like most myths, point to the unseen and unexpressed meaning as much as to any linear narrative. They have a puzzle- or riddle-like quality. The listener must discover the meaning of the story; it is not delivered or explained. Those particularly drawn to the myths and an understanding of those myths can return over and over to the story, seeking to untangle the broader or deeper connections that give a larger meaning to the story. It becomes richer and richer and deeper and deeper. When the individual is successful, an expanded version of the story is told, introducing more paradox, ambiguity, and confusion. This is repeated over and over. When one becomes a master storyteller, or "true storyteller," a myth first encountered as a child in a version told in five minutes becomes an epic told over several days, but only to those and by those who have penetrated the mystery at the heart of the myth, the rich connections that give order and meaning not just to that particular story, but to an entire cosmology of Ojibway culture.

In the same way as the symbolic communications that are myths and traditional stories, it can be argued that iconic images become "attractors" that help to organize the emerging understanding of individuals who seek that understanding. There has been considerable interest in recent years in the relationship between Jungian psychology and complexity theory (Van Eenwyk 1997, Conforti 2013) and between human consciousness and complexity concepts such as attractors (Friston 2017). Van Eenwyk (1997), for example, draws a comparison between symbols and the saddle points of Hopf bifurcations (Fig. 7). The oscillations are created by a movement away from the saddle point into chaos and back again, which Van Eenwyk terms a process of chaotic cascades (Fig. 8). Order and disorder are held in dynamic tension.

\section{This brings us to perhaps the most important discovery about deterministic chaos: that it can actually lead to higher levels of order than existed prior to its onset. In other words, chaos can generate greater complexity within a dynamic. Higher levels of sophistication ... improve adaptive capacities. Astonishing as it may seem, chaos seems to be essential not only for the survival of the organism, but for its development as well. (Van Eenwyk 1997:65)}

For Jung, this tension is key to psychic development and individuation. We are attracted to symbols as a means of selforganization. Like the development of the Ojibwa storyteller, the scientist or artist returns to an iconic image in an effort to make sense of data, as a touch point for new explorations. Very enduring symbols or iconic images, however, are as puzzling as they are comforting. When we return to them, we see them in a new way, allowed by our experimentation, but a mystery remains, pushing both artists and scientists to further explorations. A succinct example is Monet's repeated paintings of haystacks, both similar and different. Photographs from the archipelago outside Stockholm, shot from the same point over three decades, depict an environment in continuous flux that still remains (Fig. 9). 
In science, again, one thinks of the double helix in genetics, the adaptive cycle in resilience theory (Fig. 10), or the catastrophe fold in complexity theory, which have stimulated multiple disciplinary and interdisciplinary explorations. The adaptive cycle, for example, has stimulated research in organizations, leadership, innovation, disaster management, and ecosystem management (Gunderson and Holling 1995, King 1995, Westley et al. 2006, Walker and Westley 2011, Hurst 2012).

In summary, an important aspect of symbols, according to Eliade (1971), is that they do not seem to draw us through time as much as taking us back to a primordial experience of implicate order that is eternally present. Symbols draw us into a sense of time that is diachronic, cutting through the forward momentum of history. Eliade (1971) deals with this at length in his discussion of the "eternal return."

In this sense, iconic images act as symbols that orient exploration, providing a "still point in a turning world," as the poet T. S. Eliot (1941:3) described it. As such, they become associated with whole bodies of work by individual artists and scientists and by whole paradigms in art and science (Kuhn 1962).

\section{Iconic images as transformers}

The concept of transformation can be defined as the action of changing in form, shape, or appearance: metamorphosis. The word is derived from the Latin: trans (across, to, or on the farther side of, beyond, over) and formâre (to form). It suggests that to transform means to first lose form or shape and then, on the other side of chaos, to reform into something new: a sea change of nature, form, or function. Consistent with the Jungian notion of the collective conscious/chaos theory, we would suggest that transformation, whether cultural, ecological, or individual, involves a process of descending into confusion, chaos, or disorder. Iconic or symbolic imagery can help facilitate transformation by providing a means to stand "in ordered relationship to this flux" (Hollis 2000:18). It provides not only the still point, but also a place of integrity to which we can return from exploration, to begin new explorations.

The archetypes are the numinous structural elements of the psyche and possess a certain autonomy and specific energy which enables them to attract, out of the conscious mind, those contents which are best suited to themselves. The symbols act as transformers, their function being to convert libido from a "lower" to a "higher form." (Jung 1973:5,308)

So, for example, an iconic image, such as the adaptive cycle, allows a scientist to explore more possibilities, to move further from land, using gained experiences for new discoveries, because the iconic image continues to offer a compass, a point of orientation, serving as an attractor around which to self-organize.

One may argue that the iconic images of observing planet Earth and its biosphere from space serve as a compass, a point of orientation when confronted with chaos and disorder. Clearly, and in opposition to mind-sets and worldviews that have emerged during the great acceleration of the industrial era (Steffen et al. 2015), the iconic images of the living planet, of a deep reality, help provide meaning and direction (Heise 2008), as a guide in transforming beliefs and actions to operate in concert with the resilience of the biosphere (Folke et al. 2016). Such iconic images are helpful in the search for sustainable pathways in turbulent times on the human-dominated planet subject to climate change and dynamic social-ecological challenges (Westley et al. 2011).

However, the capacity to descend into confusion, chaos, or disorder is one that requires a certain disposition in both scientists and artists. Part of this is the capacity to trust that images, deriving from processes such as dreams and sudden associations, carry important messages. This is an easier concept for artists to grasp; they are used to intuition and surprise as guides and technique as their servant. For many scientists, however, the sudden inspiration or dream is potentially suspect, an intrusion of unpredictability into a process in which precision, control, and replicability are paramount. However, in the broader exploration, which is science, moments of sudden and breathtaking collapse and reorganization that forever transform the scientist's understanding of the problem are far from rare. It would appear that moments that transform are rarely arrived at by deliberate and logical reasoning. It also appears that when those transformative insights occur, they often come in the form of images or pictures as opposed to words.

But the fact that the unconscious prefers avoiding verbal instructions pretty much altogether-even where they would appear to be quite useful - suggests rather strongly that it doesn't much like language and even that it doesn't trust it. (McCarthy 2017)

McCarthy recounts the many occasions when the answer to scientific or mathematical problems comes in the form of images, received in dreams or dreamlike states. "Why is the unconscious so loathe to speak to us? Why the images, metaphors, pictures? Why the dreams, for that matter," he asks.

The answer does not pose a problem for the artist, who feels much more comfortable with the direct use of metaphor and image and sees a kind of truth in synthesis as opposed to analysis (Bayles and Orland 2001). It is perhaps harder for the scientist to see in dreams, images, and intuitive leaps a "deeper" understanding, one that undergirds the truth arrived at by pure logic. However, often scientists, like artists, return to and honor those iconic images that express that deeper understanding more profoundly and more efficiently than words or formulas.

So we can see the transformative power of images within the individual psyche and work of both artist and scientist. Once externalized, however, does the image transform? The difference between the dream that presents itself as a solution to an individual problem in the mind of an individual scientist or artist is that for an image to become iconic, it must stimulate the same experience of revelation, of transformed sensibility in a much larger group. It must also produce a new cascade of action or activity. In this respect, there is some evidence that symbols are moving, that pictures and images are more likely to stimulate emotion than words, and that emotion, in turn, is a key element of motivation and action (Mintzberg and Westley 2001, Hochschild 2012, Cialdini 2016). The more iconic the image, the greater its power to attract multiple interpretations, weaving a wordless link between these. In art and in science, iconic images become a beacon for new schools of thought and practice, which, like Kuhn's paradigms, run their course through time.

Ultimately, then, iconic imagery is a powerful bridge between art and science and, potentially, points to what the two have in 
common. In both art and science, there is a search for an underlying truth, an implicate order. In varying degrees, both art and science use imagery that arises from the unconscious as an important signpost, pointing to the implicate order for which they are searching. Artists are perhaps more comfortable with the phase of disorder that such a search involves and are perhaps more suspicious of using iconic images as guides for extensive periods of time.

\section{Artists are at home with not-knowing, we are experts at ignorance. Art is not about answers but about questions. The poet, John Keats, talked about this as negative capability. Samuel Taylor Coleridge gave us the term "willing suspension of disbelief" which undergirds reception in most art work: novels, movies, theatre. As spectators, we are experts at placing "knowing" on temporary hold. That's some of what we are cultivating. A willingness to set aside judgments, to cultivate the capacity to abide uncertainties, to engage imagination not hindered by reality. (Clark and Carpenter 2014:1)}

Scientists, on the other hand, may be more suspicious of the intuitive leap, the image drawn from dreams, but once a breakthrough is represented in an elegant image and widely shared, they are more likely to allow it to act as a guide to thinking and further development of theory and scientific insight.

Despite these distinctions, iconic images and the role they play in both art and science offer a fertile starting point for dialogue and exploration. Collaboration in the art-science interface undoubtedly has the potential to reveal and explore the role of symbols in unlocking dimensions and elements of the human spirit that correspond to the dimensions and elements of the biosphere. Such a focus can create space for reflection, thoughtfulness, and meaning. It may help stimulate intuition and create excitement for opening up unclear and unknown dimensions and elements of reality of the complex intertwined world of the 21 st century.

Responses to this article can be read online at: http://www.ecologyandsociety.org/issues/responses. php/10495

\section{Acknowledgments:}

We would like to acknowledge the South American Institute for Resilience and Sustainability and the rich discussions held there with colleagues Angela Lieble, Diego Galifassi, Pablo Marquet, Francisco Gazitua, and Tone Bjordam, among others, during the 2013 and 2014 workshops on reconciling art and science for transformation.

\section{LITERATURE CITED}

Bayles, D., and T. Orland. 2001. Fear and art: observations on the perils and rewards of artmaking. The Image Continuum, Santa Cruz, California, USA.

Bohm, D. 1980. Wholeness and the implicate order. Routledge, Abingdon, Oxford, UK.
Cialdini, R. 2016. Pre-suasion: a revolutionary way to influence and persuade. Simon and Schuster, New York, New York, USA.

Clark, L. B., and S. R. Carpenter. 2014. Introduction. Pages 1-4 in Imagining resilience: art-science collaboration for sustainability (Maldonado, Uruguay, 15-18 December). South American Institute for Resilience and Sustainability Studies, Maldonado, Uruguay.

Conforti, M. 2013. Field, form, and fate: patterns in mind, nature and psyche. Spring Journal Books, New Orleans, Louisiana, USA.

Curtis, D. J., N. Reid, and G. Ballard. 2012. Communicating ecology through art: what scientists think. Ecology and Society 17(2):3. http://dx.doi.org/10.5751/ES-04670-170203

Deeley, J. 1982. Introducing semiotics: its history and doctrine. Indiana University Press, Bloomington, Indiana, USA.

Durkheim, E. 2001 (1912). The elementary forms of the religious life. Oxford University Press, Oxford, UK.

Eliade, M. 1971. The myth of the eternal return: cosmos and history. Princeton University Press, Princeton, New Jersey, USA.

Eliot, T. S. 1941. Burnt Norton. Pages XX in Four quartets. Harcourt, New York, New York, USA.

Evans, J., and P. Jones. 2008. Rethinking sustainable urban regeneration: ambiguity, creativity, and the shared territory. Environment and Planning A: Economy and Space 40:1416-1434. http://dx.doi.org/10.1068/a39293

Folke, C., R. Biggs, A. V. Norström, B. Reyers, and J. Rockström. 2016. Social-ecological resilience and biosphere-based sustainability science. Ecology and Society 21(3):41. http://dx.doi.org/10.5751/ ES-08748-210341

Folke, C., and L. Hall. 2014. Reflections on people and the biosphere. Bokförlaget Langenskiöld, Stockholm, Sweden.

Friston, K. 2017. The mathematics of mind time. Aeon, 18 May. [online] URL: https://aeon.co/essays/consciousness-is-not-athing-but-a-process-of-inference?utm source $=$ Aeon +

Newsletter\&utm campaign=78f956e309-EMAIL CAMPAIGN2017 05 16\&utm_medium $=$ email\&utm term $=0 \_411 \mathrm{a} 82 \mathrm{e} 59 \mathrm{~d}-\mathrm{-}$ 78f956e309-69449461

Gould, S. J. 2000. Crossing over: where art and science meet. Three Rivers, New York, New York, USA.

Gunderson, L., and C. S. Holling. 1995. Panarchy: understanding transformation in human and natural systems. Free, Washington, D.C., USA.

Heise, U. K. 2008. Sense of place and sense of planet: the environmental imagination of the global. Oxford University Press, Oxford, UK. http://dx.doi.org/10.1093/acprof:oso/97801953356$\underline{37.001 .0001}$

Hochschild, A. R. 2012. The managed heart. University of California Press, Berkeley, California, USA.

Hollis, J. 2000. The archtypal imagination. Texas A\&M Press, College Station, Texas, USA.

Hug, L. A., B. J. Baker, K. Anantharaman, C. T. Brown, A. J. Probst, C. J. Castelle, C. N. Butterfield, A. W. Hernsdorf, Y. 
Amano, K. Ise, Y. Suzuki, N. Dudek, D. A. Relman, K. M. Finstad, R. Amundson, B. C. Thomas, and J. F. Banfield. 2016. A new view of the tree of life. Nature Microbiology 1:16048. http:// dx.doi.org/10.1038/nmicrobiol.2016.48

Hurst, D. 2012. The new ecology of leadership. Columbia University Press, New York, New York, USA.

Huxley, A. 1946. The perennial philosophy. Harper Perennial Modern Classics, New York, New York, USA.

Jung, C. G. 1959/1969. The archetypes and the collective unconscious: collected works of C.G. Jung. Volume 9, Part 1. Bollingen Series. Princeton University Press, Princeton, New Jersey, USA.

Jung, C. G. 1973. The collected works. Volume 5, symbols of transformation. E. C. Hull, editor. Princeton University Press, Princeton, New Jersey, USA.

Kahneman, D. 2011. Thinking, fast and slow. Farrar, Straus, and Giroux, New York, New York, USA.

King, A. 1995. Avoiding ecological surprise: lessons from long standing communities. Academy of Management Review 20 (4):961-985. http://dx.doi.org/10.2307/258962

Kuhn, T. 1962. The structure of scientific revolutions. University of California Press, Berkeley, California, USA.

Lu, K. 2012. Jung, history and his approach to the psyche. Journal of Jungian Scholarly Studies 8(9):1-24.

McCarthy, C. 2017. The Kerulé problem: where did language come from. Nautilus 47, 20 April. [online] URL: http://nautil.us/ issue/47/consciousness/the-kekul-problem

Mintzberg, H., and F. Westley. 2001. Decision making: it's not what you think. Sloan Management Review 42(3):89-94.

O'Brien, K., and G. Hochachka. 2010. Integral adaptation to climate change. Journal of Integral Theory and Practice 5:89-102.

Österblom, H., M. Scheffer, F. R. Westley, M. Van Esso, J. Miller, and J. Bascompte. 2015. A message from magic to science: seeing how the brain can be tricked may strengthen our thinking. Ecology and Society 20(4):16. http://dx.doi.org/10.5751/ES-07943-200416

Peirce, C. S. 1958/1899. Signs and the categories. Pages 220-245 in A. W. Burks, editor. The collected papers of Charles Sanders Peirce. Volume 8, reviews, correspondence and bibliography. Harvard University Press, Cambridge, Massachusetts, USA.

Root-Bernstein, R. S. 2000. Science in culture. Nature 407:134. http://dx.doi.org/10.1038/35025133

Scheffer, M., J. Bascompte, T. K. Bjordam, S. R. Carpenter, L. B. Clarke, C. Folke, P. Marquet, N. Mazzeo, M. Meerhoff, O. Sala, and F. R. Westley. 2015. Dual thinking for scientists. Ecology and Society 20(2):3. http://dx.doi.org/10.5751/ES-07434-200203

Steffen, W., W. Broadgate, L. Deutsch, O. Gaffney, and C. Ludwig. 2015. The trajectory of the Anthropocene: the great acceleration. Anthropocene Review 2:81-98. http://dx.doi.org/10.1177/205301$\underline{9614564785}$

Taimni, I. K. 1974. Man, god and the universe. Quest Books. Theosophical Publishing House, London, UK.
Tillich, P. 1951. Systematic theology. Volume 1. University of Chicago Press, Chicago, Illinois, USA.

Tillich, P. 1957. The dynamics of faith. Harper \& Row, New York, New York, USA.

Uzzi, B., S. Mukherjee, M. Stringer, and B. Jones. 2013. Atypical combinations and scientific impact. Science 342:468-472. http:// dx.doi.org/10.1126/science.1240474

Van Eenwyk, J. 1997. Archetypes and strange attractors. Inner City Books, Toronto, Ontario, Canada.

Vervoort, J. M., D. H. Keuskamp, K. Kok, R. van Lammeren, T. Stolk, T. A. Veldkamp, J. Rekveld, R. Schelfhout, B. Teklenburg, A. Cavalheiro Borges, S. Jánokóva, W. Wits, N. Assmann, E. Abdi Dezfouli, K. Cunningham, B. Nordeman, and H. Rowlands. 2014. A sense of change: media designers and artists communicating about complexity in social-ecological systems. Ecology and Society 19(3):10. http://dx.doi.org/10.5751/ES-06613-190310

Walker, B., and F. Westley. 2011. Perspectives on resilience to disasters across sectors and cultures. Ecology and Society 16(2):4. [online] URL: http://dx.doi.org/10.5751/ES-04070-160204

Westley, F., P. Olsson, C. Folke, T. Homer-Dixon, H. Vredenburg, D. Loorbach, J. Thompson, M. Nilsson, E. Lambin, J. Sendzimir, B. Banarjee, V. Galaz, and S. van der Leeuw. 2011. Tipping toward sustainability: emerging pathways of transformation. Ambio 40:762-780. http://dx.doi.org/10.1007/s13280-011-0186-9

Westley, F., B. Zimmerman, and M. Q. Patton. 2006. Getting to maybe: how the world is changed. Random House, Toronto, Ontario, Canada.

Wilson, E. O. 1998. Consilience: the unity of knowledge. Alfred A. Knopf, New York, New York, USA. 